Article

\title{
Elevated Lactate Levels in Acute Pulmonary Embolism Are Associated with Prothrombotic Fibrin Clot Properties: Contribution of NETs Formation
}

\author{
Michał Ząbczyk ${ }^{1,2,+} \oplus$, Joanna Natorska ${ }^{1,2,+}$, Agnieszka Janion-Sadowska $^{3}$, \\ Krzysztof P. Malinowski ${ }^{4}\left(\mathbb{D}\right.$, Marianna Janion ${ }^{3}$ and Anetta Undas ${ }^{1,2,3, *}$ \\ 1 Institute of Cardiology, Jagiellonian University Medical College, 31-202 Krakow, Poland; \\ michal.zabczyk@uj.edu.pl (M.Z.); j.natorska@szpitaljp2.krakow.pl (J.N.) \\ 2 John Paul II Hospital, 31-202 Krakow, Poland \\ 3 The Faculty of Medicine and Health Sciences, The Jan Kochanowski University, 25-317 Kielce, Poland; \\ ajanion@o2.pl (A.J.-S.); asianat@o2.pl (M.J.) \\ 4 Institute of Public Health, Faculty of Health Sciences, Jagiellonian University Medical College, \\ 31-126 Krakow, Poland; krzysztof.piotr.malinowski@gmail.com \\ * Correspondence: mmundas@cyf-kr.edu.pl \\ + These authors contributed equally to this work.
}

Received: 28 February 2020; Accepted: 27 March 2020; Published: 30 March 2020

\begin{abstract}
Background: Elevated plasma lactate levels correlate with high mortality rate in acute pulmonary embolism (PE) patients. We hypothesized that elevated lactate levels correlate with prothrombotic fibrin clot properties and enhanced neutrophil extracellular trap (NET) formation in acute PE. Methods: As many as 126 normotensive acute PE patients (aged $58 \pm 14$ years) were enrolled. Plasma fibrin clot permeability $\left(\mathrm{K}_{\mathrm{s}}\right)$, clot lysis time (CLT), endogenous thrombin potential (ETP), citrullinated histone H3 (citH3), and plasminogen activator inhibitor-1 antigen (PAI-1), together with plasma L-lactate levels were evaluated on admission. Results: Lactate levels $\geq 2 \mathrm{mM}$ were found in $70(55.6 \%)$ patients in whom we observed $29 \%$ higher neutrophil count and $45 \%$ elevated plasma citH3 levels. Elevated lactate levels were associated with more prothrombotic fibrin properties as reflected by $11 \%$ reduced $\mathrm{K}_{\mathrm{s}}, 13 \%$ longer CLT, along with $11 \%$ increased ETP. Lactate levels were positively associated with plasma citH3 concentrations, ETP, CLT, and PAI-1 ( $p<0.05)$. An increase of lactate levels by $1 \mathrm{mM}$ leading to the prolongation of CLT by $8.82 \mathrm{~min}$ was shown in the linear regression. Conclusions: Our findings suggest a new mechanism contributing to a negative impact of elevated lactate levels on prognosis in acute PE patients, in particular hypofibrinolysis, associated with enhanced NET formation.
\end{abstract}

Keywords: acute thrombosis; fibrinolysis; lactate; NETosis; pulmonary embolism

\section{Introduction}

Acute pulmonary embolism (PE), isolated or combined with deep-vein thrombosis (DVT), is the major cause of mortality or hospitalization due to venous thromboembolism (VTE) [1]. Mortality related to PE has not been reduced for many years, mainly due to a short-term prognosis, and treatment strategies remain challenging [2]. Growing evidence indicates that right ventricular (RV) dysfunction or injury markers, namely increased brain natriuretic peptides (BNP) or troponin levels along with RV dysfunction, indicate worse prognoses $[3,4]$. The currently recommended markers to classify PE severity and the risk of early death have a suboptimal predictive value [4].

Lactate levels are considered as a laboratory parameter associated with disturbed oxygen supply in tissues [5]. Increased lactate levels have been also proposed as a prognostic marker in sepsis [6]. 
Vanni et al. have shown plasma lactate level $\geq 2 \mathrm{mM}$ to be associated with higher mortality of acute PE patients, independent of shock, hypotension, RV dysfunction, or cardiac injury markers [7]. Moreover, elevated plasma lactate level has been considered as a predictor of short-term PE-related adverse events, suggesting that this parameter may be important as a decision-making factor during PE care [8].

$\mathrm{L}(+)$-Lactate is a main stereo-isomer of lactate present in human blood. $\mathrm{D}(-)$-lactate concentrations are low, about $1 \%-5 \%$ of those of $\mathrm{L}(+)$-lactate. A previous in vitro study performed using bovine neutrophils showed that lactic acid is able to activate neutrophil extracellular trap (NET) release and promote neutrophil adhesion [9]. Moreover, lactic-mediated NET formation was dependent on peptidyl arginine deaminase 4 (PAD4) [9], a key enzyme in DNA decondensation and NETosis. Several studies have explored diverse mechanisms by which NETs can enhance thrombosis [10]. It has been shown that NETs activate platelets and provide a scaffold for red blood cells and procoagulant proteins, including von Willebrand factor (F), fibronectin, fibrinogen [10], FXII [11], and tissue factor (TF) [12], demonstrating the complex crosstalk between blood components and NET formation [13]. Fibrin clots enriched in histone-DNA complexes had higher stability, rigidity, and prolonged clot lysis time [14]. NETs have been shown to increase in vitro thrombin generation in septic patients' blood [15]. As far as we know, there are no reports showing whether lactate concentrations in acute PE patients are linked to the prothrombotic changes in circulating blood.

Thus, we aimed to investigate if plasma lactate levels are correlated with NETosis-mediated plasma fibrin clot property alterations in acute PE patients.

\section{Material and Methods}

\subsection{Patients}

As many as 126 acute symptomatic PE white patients were recruited from December 2016 to March 2019 in four cardiology centers, all of whom were emergency admissions. This groups was described in detail previously [16]. Briefly, the diagnosis of PE was based on the presence of typical symptoms and positive results of high resolution spiral computed tomography. The following exclusion criteria were applied: diagnosed cancer, pregnancy, postpartum period, high-risk PE with shock or hypotension, ischemic stroke in the past 3 months, myocardial infarction in the past 3 months, end-stage kidney disease, vitamin $\mathrm{K}$ antagonist use, and anti-Xa activity $\geq 0.2 \mathrm{U} / \mathrm{mL}$ suggesting the effect of heparins.

A simplified PE severity index (sPESI) was assessed [4]. sPESI equal to 0 indicated low-risk PE. Normotensive PE patients with sPESI of $\geq 1$ represented an intermediate-risk group. Using the ESC approach, patients with both RV dysfunction (by echocardiography or CT angiography) and elevated cardiac troponin $\mathrm{T}(\mathrm{TnT})$ represented an intermediate-high-risk category, while those with normal RV or TnT levels were classified as an intermediate-low-risk group.

$\mathrm{RV}$ dysfunction was recognized in the presence of RV dilatation in the absence of significant left ventricular disease, based on the ESC guidelines [4]. DVT was diagnosed if thrombi were visualized in lower extremity deep veins using color duplex sonography performed within the first $48 \mathrm{~h}$ since enrolment. We categorized VTE episodes as those without any identifiable cause (unprovoked) or those associated with well-established factors (provoked) including known cancer, recent major surgery or trauma, plaster cast or hospitalization (within the preceding 28 days), or pregnancy or delivery in the past 3 months. Arterial hypertension was defined as elevated systolic and/or diastolic blood pressure $\geq 140 / 90 \mathrm{mmHg}$ in consecutive measurements after clinical stabilization, or the current antihypertensive therapy. Coronary artery disease (CAD) was diagnosed as a history of documented myocardial infarction, hospitalization due to unstable angina, or prior elective percutaneous coronary intervention. Heart failure was diagnosed if the New York Heart Association (NYHA) class was 2 or higher or/and the left ventricular ejection fraction was less than $45 \%$. The definition of diabetes was as follows: fasting plasma glucose $\geq 7.0 \mathrm{mmol} / \mathrm{L}(126 \mathrm{mg} / \mathrm{dL})$ on two separate occasions or the current hypoglycemic treatment. 
The study participants were followed by telephone contacts and clinic visits scheduled at 3 and 12 months since the index PE event. The primary composite endpoint was the occurrence of recurrent PE and/or DVT or death. The Jagiellonian University Ethical Committee approved the study, and participants provided informed written consent.

\subsection{Laboratory Variables}

Before initiation of anticoagulant therapy on admission, blood samples were collected from an antecubital vein with minimal stasis. Blood cell count, glucose, creatinine, prothrombin time (international normalized ratio, INR), activated partial thromboplastin time (aPTT), lipid profile, D-dimer, N-terminal B-type natriuretic propeptide (NT-proBNP), and high-sensitivity TnT were assayed by routine laboratory techniques in the hospital laboratory. Positive high-sensitivity TnT was defined as a value $\geq 14 \mathrm{pg} / \mathrm{mL}$ and positive NT-proBNP as a value $\geq 600 \mathrm{pg} / \mathrm{mL}$ [4]. FVIII activity (Siemens Healthcare Diagnostics, Marburg, Germany) was measured by the Behring Coagulation System (Siemens). Anti-FXa activity was measured using a chromogenic assay (BIOPHEN, Hyphen-Biomed, Neuville-Sur-Oise, France). Fibrinogen was determined using the Clauss method. C-reactive protein (CRP) was measured by nephelometry (Siemens Healthcare Diagnostics). Plasma L(+)-lactate (Abcam, Cambridge, UK; sensitivity $0.02 \mathrm{mM}$, detection range $0.02-10 \mathrm{mM}$ ) levels were determined by an ELISA test. Based on the literature, abnormal plasma lactate concentrations were defined as values of $2 \mathrm{mM}$ or greater [5,7]. P-selectin and platelet factor 4 (PF-4) (both Quantikine, R\&D Systems, Inc., Minneapolis, MN, USA), as well as fibrinolysis inhibitors-plasminogen activator inhibitor-1 (PAI-1) antigen and thrombin activatable fibrinolysis inhibitor (TAFI) activity (both from Hyphen-Biomed, Neuville-Sur-Oise, France)—were assayed by ELISAs. Plasminogen and $\alpha 2$-antiplasmin ( $\alpha 2 \mathrm{AP})$ levels were determined by chromogenic assays (Siemens). We also determined in plasma citrullinated histone H3 (citH3) (Cayman Chemical, Ann Arbor, MI, USA).

\subsection{Fibrin Permeation Analysis}

Fibrin clot permeation was determined as previously described [17]. Briefly, citrated plasma was mixed with $20 \mathrm{mM}$ calcium chloride and $1 \mathrm{U} / \mathrm{mL}$ human thrombin (Merck KGaA, Darmstadt, Germany). Tubes containing the clots were connected to a reservoir of a Tris buffer, and we recorded the buffer volume percolating through the gels during one hour. A permeation coefficient $\left(\mathrm{K}_{\mathrm{s}}\right)$, Darcy's constant, which is an indirect measure of the average pore size in the fiber network, was calculated from the equation: $K_{s}=Q \times L \times \eta / t \times A \times \Delta p$, where $Q$ is the flow rate in time $t ; L$ is the length of a fibrin gel; $\eta$ is the viscosity of liquid (in poise); $\mathrm{A}$ is the cross-sectional area (in $\mathrm{cm}^{2}$ ); and $\Delta \mathrm{p}$ is a differential pressure (in dyne $/ \mathrm{cm}^{2}$ ).

\subsection{Plasma Clot Lysis Assay}

Fibrinolysis capacity was determined using a clot lysis time (CLT), as described in [18]. Briefly, $15 \mathrm{mM}$ calcium chloride, $0.5 \mathrm{U} / \mathrm{mL}$ human thrombin (Merck), $15 \mu \mathrm{M}$ phospholipid vesicles (Rossix, Mölndal, Sweden), and $20 \mathrm{ng} / \mathrm{mL}$ recombinant tPA (rtPA, Boehringer Ingelheim, Germany) were added to citrated plasma samples and then transferred to a microtiter plate. Absorbance was determined at $405 \mathrm{~nm}$ at $37^{\circ} \mathrm{C}$. We defined CLT as the time from the midpoint of the clear-to-maximum-turbid transition to the midpoint of the maximum-turbid-to-clear transition.

\subsection{Endogenous Thrombin Potential}

We used calibrated automated thrombography (CAT; Thrombinoscope BV, Maastricht, the Netherlands) to determine a key measure of thrombin generation in plasma samples, namely endogenous thrombin potential (ETP), the area under the curve, generated using the fluorometer (Ascent Reader, Thermolabsystems OY, Helsinki, Finland).

Briefly, we added to platelet-poor plasma the reagent containing $5 \mathrm{pM}$ recombinant TF, $4 \mu \mathrm{M}$ phosphatidylserine/phosphatidylcholine/phosphatidylethanolamine vesicles, and FluCa 
solution (HEPES, pH 7.35, $100 \mathrm{nM} \mathrm{CaCl}_{2}, 60 \mathrm{mg} / \mathrm{mL}$ bovine albumin, and $2.5 \mathrm{mM}$ Z-Gly-Gly-Arg-7-amino-4-methylcoumarin). Each plasma sample was analyzed at $37^{\circ} \mathrm{C}$.

\subsection{Statistics}

Variables are presented as numbers and percentages, mean \pm standard deviation (SD) or median and interquartile range (IQR), as appropriate. Normality was assessed by the Shapiro-Wilk test. Equality of variances was assessed using Levene's test. Differences between groups were compared using the Student or the Welch t-test depending on the equality of variances for normally distributed variables. The Mann-Whitney U-test was used for non-normally distributed variables. Categorical variables were compared by the Pearson chi-squared test or Fisher's exact test. Multiple group comparisons were performed using analysis of variance (ANOVA) or the Kruskal-Wallis test. The Tukey-Kramer HSD test or Steel-Dwass method was used for the post-hoc comparisons. Univariate and multivariate logistic and linear regression models were performed to identify determinants of prolonged CLT. The multivariate model was fitted using backward stepwise regression. Variables that were associated with the prolonged CLT with a significance level of $p<0.2$ in the bivariate models were selected for possible inclusion in the multivariate logistic regression models. All statistical analysis were performed using STATISTICA software Version 12.5 (StatSoft STATISTICA ${ }^{\mathrm{TM}}$, Krakow, Poland).

\section{Results}

We studied 126 patients aged $58.2 \pm 14.4$ years (Table 1$)$. Positive TnT was found in $42(33.3 \%)$, and positive NT-proBNP in 47 (37.3\%) patients, while RV dysfunction was observed in 46 individuals (36.5\%).

Table 1. Characteristics of patients with acute pulmonary embolism (PE) stratified according to serum lactate levels.

\begin{tabular}{|c|c|c|c|c|}
\hline Variable & $\begin{array}{l}\text { Acute PE Patients, } \\
n=126\end{array}$ & $\begin{array}{c}\text { Lactate } \geq 2 \mathrm{mM} \\
\mathrm{n}=70(55.6 \%)\end{array}$ & $\begin{array}{c}\text { Lactate }<2 \mathrm{mM} \\
\mathrm{n}=56(44.4 \%)\end{array}$ & $p$-Value \\
\hline Age, years & $58.2 \pm 14.4$ & $60.9 \pm 13.3$ & $54.9 \pm 15.2$ & 0.02 \\
\hline Sex (male), n (\%) & $66(52.4)$ & $39(55.7)$ & $27(48.2)$ & 0.40 \\
\hline Body-mass index, $\mathrm{kg} / \mathrm{m}^{2}$ & $28.1 \pm 5.1$ & $27.6 \pm 4.6$ & $28.8 \pm 5.6$ & 0.20 \\
\hline Current smokers, n (\%) & $25(19.8)$ & $15(21.4)$ & $10(17.9)$ & 0.62 \\
\hline \multicolumn{5}{|c|}{ Comorbidities and medications } \\
\hline Time from PE symptom onset, days & $4(2-7)$ & $3(1-7)$ & $5(2.5-7)$ & 0.08 \\
\hline Low risk $\mathrm{PE}, \mathrm{n}(\%)$ & $20(15.9 \%)$ & $8(11.4)$ & $12(21.4)$ & 0.13 \\
\hline Intermediate-low risk PE, $\mathrm{n}(\%)$ & $77(61.1 \%)$ & $39(55.7)$ & $38(67.9)$ & 0.17 \\
\hline Intermediate-high risk PE, n (\%) & $29(22.2 \%)$ & $23(32.9)$ & $6(10.7)$ & 0.0033 \\
\hline First ever PE, n (\%) & $117(92.9)$ & $66(94.3)$ & $51(91.1)$ & 0.49 \\
\hline Concomitant DVT, n (\%) & $71(56.3)$ & $43(61.4)$ & $28(50)$ & 0.20 \\
\hline Coronary heart disease, n (\%) & $50(39.7)$ & $34(48.6)$ & $16(28.6)$ & 0.02 \\
\hline Hypertension, n (\%) & $68(54)$ & $38(54.3)$ & $30(53.6)$ & 0.94 \\
\hline Heart failure, n (\%) & $25(19.8)$ & $18(25.7)$ & $7(12.5)$ & 0.07 \\
\hline Diabetes mellitus, n (\%) & $42(33.3)$ & $28(40)$ & $14(25)$ & 0.08 \\
\hline Aspirin use, $\mathrm{n}(\%)$ & $40(31.7)$ & $26(37.1)$ & $14(25)$ & 0.15 \\
\hline Statins use, n (\%) & $77(61.1)$ & $44(62.9)$ & $33(58.9)$ & 0.65 \\
\hline \multicolumn{5}{|c|}{ Laboratory investigations } \\
\hline White blood cell count, $10^{3} / \mu \mathrm{L}$ & $7.03(5.50-9.18)$ & $8.20(6.40-10.35)$ & $5.99(5.02-7.50)$ & $<0.0001$ \\
\hline Neutrophil count, $10^{3} / \mu \mathrm{L}$ & $3.82(3.10-5.77)$ & $4.14(3.55-6.69)$ & $3.21(2.59-4.06)$ & $<0.0001$ \\
\hline Hemoglobin, g/dL & $13.8 \pm 1.6$ & $13.9 \pm 1.5$ & $13.6 \pm 1.6$ & 0.29 \\
\hline Platelet count, $10^{3} / \mu \mathrm{L}$ & $220(191-283)$ & $221(198-293)$ & $218(188-266)$ & 0.65 \\
\hline Fibrinogen, $\mathrm{g} / \mathrm{L}$ & $3.26(2.76-3.88)$ & $3.35(2.78-4.10)$ & $3.17(2.73-3.62)$ & 0.09 \\
\hline High-sensitivity CRP, mg/L & $3.65(1.70-12.50)$ & $3.51(1.78-14.91)$ & $4.20(1.77-9.38)$ & 0.65 \\
\hline D-dimer, ng/mL & $3233(1661-5325)$ & $3102(1622-5293)$ & $3233(1742-5642)$ & 0.80 \\
\hline NT-proBNP, pg/mL & 399 (106-1045) & $491(135-1261)$ & $253(92-742)$ & 0.07 \\
\hline High-sensitivity troponin $\mathrm{T}, \mathrm{pg} / \mathrm{mL}$ & $7.3(1-51.4)$ & $12(6-78.4)$ & $6.5(1-40)$ & 0.16 \\
\hline Citrullinated histone $\mathrm{H} 3, \mathrm{ng} / \mathrm{mL}$ & $2.77(1.90-3.98)$ & $3.40(2.03-4.31)$ & $2.35(1.88-3.34)$ & 0.010 \\
\hline
\end{tabular}




\subsection{On Admission}

As many as $70(55.6 \%)$ patients had lactate levels $\geq 2 \mathrm{mM}$. Patients with elevated lactate levels were older and more often had a history of CAD compared to the remainder (Table 1). PE patients with intermediate-high compared to intermediate-low mortality risk had $17.2 \%$ higher plasma lactate levels (2.38 (2.13-2.48) vs. 2.03 (1.57-2.40) mM; Figure 1A). RV dysfunction was associated with elevated plasma lactate levels by $15.6 \%$ as compared to the remainder $(2.30(1.70-2.47)$ vs. $1.99(1.61-2.43) \mathrm{mM}$; Figure 1B), while subjects positive for TnT had $17.8 \%$ higher lactate levels than those with normal TnT (2.32 (1.85-2.4) vs. 1.97 (1.61-2.38) mM; Figure 1C).
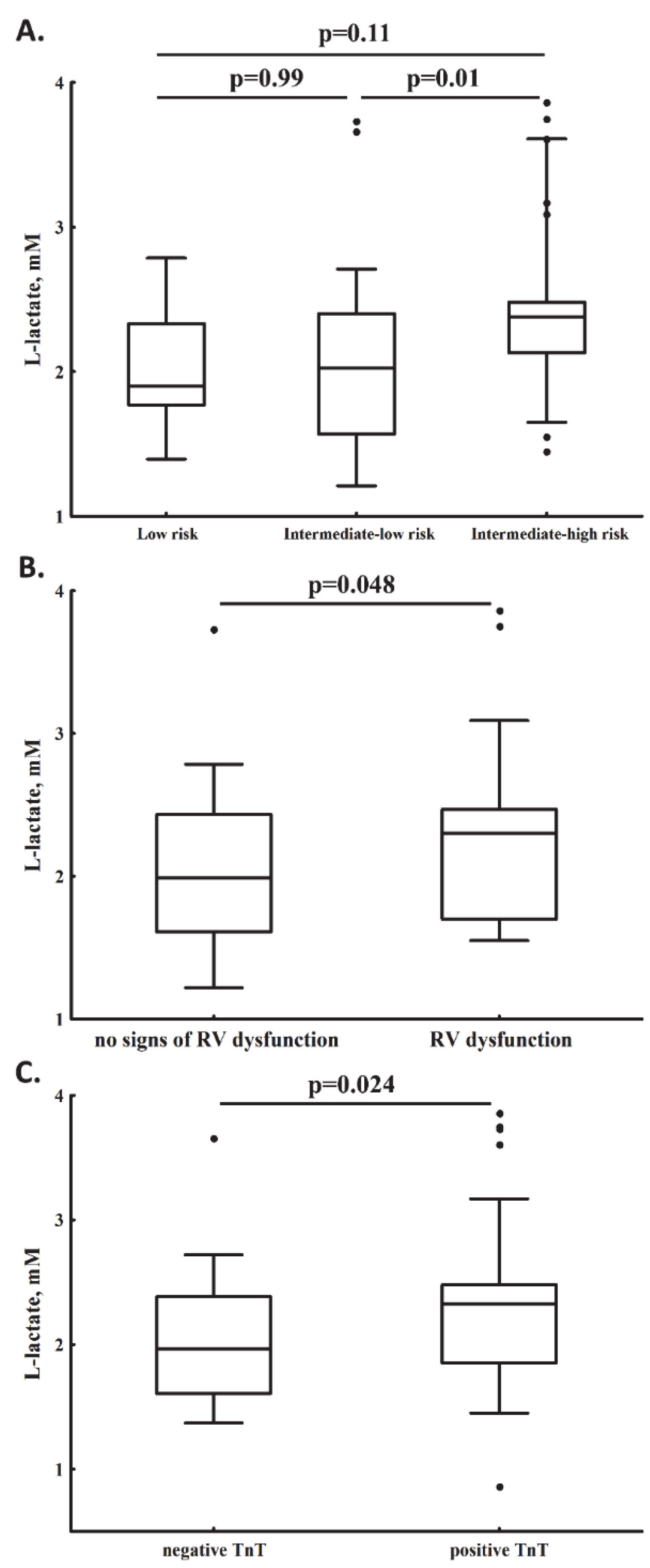

Figure 1. Plasma lactate levels determined in acute pulmonary embolism patients with low, intermediate-low, and intermediate-high early mortality risk (panel A, $p<0.05$ for ANOVA) as well as in subjects with or without right ventricular (RV) dysfunction (panel B), and in those with positive or negative troponin $\mathrm{T}$ (TnT; panel C).

Patients with plasma lactate levels $\geq 2 \mathrm{mM}$ were characterized by $36.9 \%$ higher white blood cell (WBC) and 29\% higher neutrophil counts along with $44.7 \%$ elevated citH3 levels (Table 1). Lactate concentrations were associated with WBC count $(\mathrm{r}=0.18, p=0.043)$, but not neutrophil count 
and CRP. Moreover, patients stratified according to lactate levels $\geq 2 \mathrm{mM}$ compared with the remainder had higher plasminogen activity $(+8.7 \%)$ and increased ETP $(+10.9 \%$; Table 2$)$. Elevated lactate levels were associated with more prothrombotic fibrin properties as reflected by $10.9 \%$ reduced $\mathrm{K}_{\mathrm{s}}$ and $12.6 \%$ longer CLT (Table 2), also adjusted for age and fibrinogen.

Table 2. Platelet markers, fibrinolytic proteins, thrombin generation, and fibrin clot parameters in patients with acute pulmonary embolism (PE) stratified according to serum lactate levels.

\begin{tabular}{ccccc}
\hline Variable & $\begin{array}{c}\text { Acute PE Patients, } \\
\mathbf{n = 1 2 6}\end{array}$ & $\begin{array}{c}\text { Lactate } \geq \mathbf{2} \mathbf{~ m M} \\
\mathbf{n = 7 0 ( 5 5 . 6 \% )}\end{array}$ & $\begin{array}{c}\text { Lactate }<\mathbf{2 ~} \mathbf{m M} \\
\mathbf{n = 5 6} \mathbf{( 4 4 . 4 \% )}\end{array}$ & $\boldsymbol{p}$-Value \\
\hline P-selectin, $\mathrm{ng} / \mathrm{mL}$ & $77.1 \pm 22.8$ & $77.7 \pm 23.3$ & $76.5 \pm 22.5$ & 0.77 \\
Platelet factor 4, ng/mL & $69.4 \pm 16.9$ & $69.2 \pm 17.3$ & $69.7 \pm 16.5$ & 0.85 \\
PAI-1, ng/mL & $22.9(16.7-33.2)$ & $24.6(17.3-35.4)$ & $20.8(15.8-30.3)$ & 0.11 \\
TAFI activity, \% & $100(91-110)$ & $100(91-110)$ & $100(92-110)$ & 0.63 \\
$\alpha$ 2-antiplasmin, \% & $104 \pm 14$ & $106 \pm 16$ & $102 \pm 12$ & 0.11 \\
Plasminogen, \% & $108 \pm 15$ & $112 \pm 16$ & $103 \pm 13$ & 0.0013 \\
ETP, $\mathrm{nM} \times$ min & $1660(1494-1894)$ & $1763(1510-2096)$ & $1590(1460-1742)$ & 0.013 \\
$\mathrm{~K}_{\mathrm{s}}, \times 10^{-9} \mathrm{~cm}^{2}$ & $6.50(5.46-7.40)$ & $6.19(5.20-7.10)$ & $6.95(5.95-7.50)$ & 0.026 \\
CLT, min & $106.5(95.0-121.6)$ & $111.5(98-128)$ & $99.0(88.5-113.5)$ & 0.003 \\
\hline
\end{tabular}

Data are shown as mean \pm standard deviation or median (1st quartile-3rd quartile). Abbreviations: CLT, clot lysis time; ETP, endogenous thrombin potential; $\mathrm{K}_{\mathrm{s}}$, fibrin clot permeability; PAI-1, plasminogen activator inhibitor type 1 ; TAFI, thrombin activatable fibrinolysis inhibitor.

Plasma lactate levels were positively associated with citH3 $(\mathrm{r}=0.33, p=0.0002)$, PAI-1 antigen $(\mathrm{r}=0.28, p=0.0018)$, ETP $(\mathrm{r}=0.25, p=0.0047)$, and CLT $(\mathrm{r}=0.25, p=0.0052)$, but not $\mathrm{K}_{\mathrm{s}}$. Multivariate logistic regression revealed that after exclusion of factors strongly associated with CLT such as PAI-1, plasma lactate levels along with intermediate-high PE risk, BMI, and hsCRP were the independent predictors of prolonged CLT in acute PE patients (Table 3). The linear regression analysis showed that an increase of lactate levels by $1 \mathrm{mM}$ led to the prolongation of CLT by almost 9 min (estimate $=8.82$, 95\% confidence interval 2.69-14.97 per $1 \mathrm{mM}$ increase). No such impact was noted for $\mathrm{K}_{\mathrm{s}}$ in acute PE.

Table 3. Determinants of prolonged CLT defined as values $>121.5 \mathrm{~min}$ (top quartile) in patients with acute pulmonary embolism.

\begin{tabular}{|c|c|c|c|c|}
\hline \multirow{2}{*}{ Variable } & \multicolumn{2}{|c|}{ Univariate Analysis } & \multicolumn{2}{|c|}{ Multivariate Analysis } \\
\hline & OR $(95 \% \mathrm{CI})$ & $p$ & OR $(95 \% \mathrm{CI})$ & $p$-Value \\
\hline Age (per 1 year) & $1.025(0.995-1.056)$ & 0.11 & - & \\
\hline Male sex & $0.880(0.394-1.964)$ & 0.65 & - & \\
\hline BMI (per unit) & 1.101 (1.015-1.193) & 0.02 & $1.136(1.032-1.252)$ & 0.01 \\
\hline Intermediate-high PE risk & $5.042(0.056-12.363)$ & 0.0004 & $3.197(1.174-8.703)$ & 0.023 \\
\hline RV dysfunction & $2.540(1.118-5.772)$ & 0.026 & - & \\
\hline hsCRP (per unit) & $1.022(1.005-1.039)$ & 0.93 & $1.020(1.002-1.038)$ & 0.031 \\
\hline L-lactate (per unit) & $2.416(1.238-4.713)$ & 0.0097 & $3.074(1.351-6.992)$ & 0.007 \\
\hline
\end{tabular}

Abbreviations: OR, odds ratio; $\mathrm{CI}$, confidence interval; RV, right ventricular; for other abbreviations see Tables 1 and 2 .

\subsection{Follow-up}

In total, we recorded nine (7.14\%) deaths during a 1-year follow-up, including two patients with fatal DVT combined with PE, four patients with fatal stroke, one subject with sudden cardiac death, one with major bleeding followed by fatal acute myocardial infarction, and one trauma-related death. Distal DVT episodes were recorded in two (1.6\%) subjects during follow-up. Patients who died or experienced recurrent VTE after acute PE compared to the remainder had 20.7\% higher lactate levels on admission (2.45 (2.31-2.71) vs. $2.03(1.63-2.41) \mathrm{mM}, p=0.0043$; Figure 2$)$ along with $50.5 \%$ higher citH3 levels (4.11 (3.66-5.62) vs. $2.73(1.89-3.87) \mathrm{ng} / \mathrm{mL}, p=0.00077)$. 


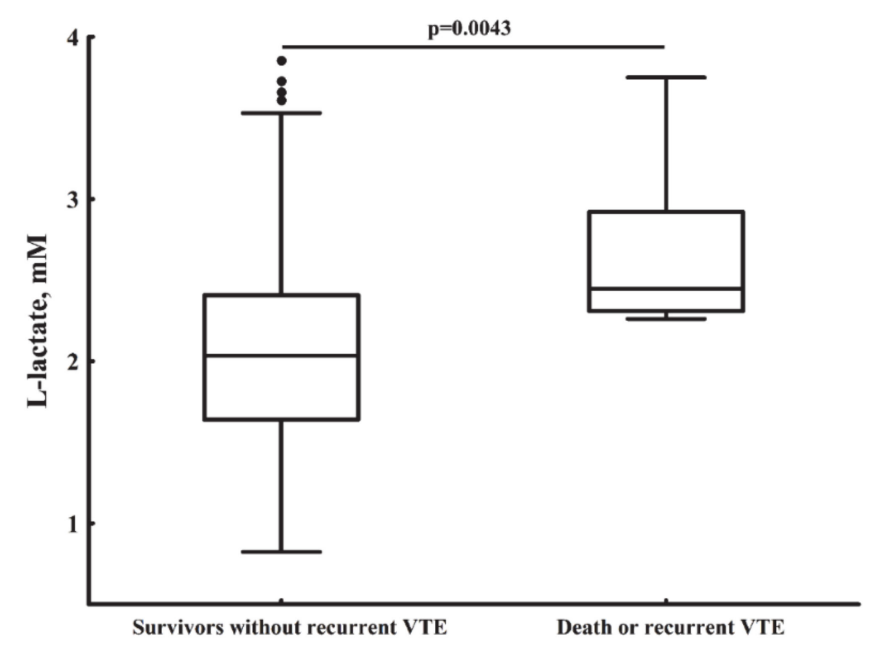

Figure 2. Plasma lactate levels assessed on admission in survivors without recurrent venous thromboembolism (VTE) vs. patients who died due to acute pulmonary embolism or its complications or experienced recurrent VTE during 1 year follow-up.

\section{Discussion}

We have shown for the first time that lactate levels $\geq 2 \mathrm{mM}$ in acute PE patients are associated with impaired plasma fibrinolytic capacity accompanied by enhanced NET formation and increased thrombin generation. The current study suggests that hyperlactatemia contributed to unfavorably altered fibrin clot characteristics recently reported by us in acute PE [16]. In line with previous studies [3,7,8], we observed that lactate levels $\geq 2 \mathrm{mM}$ are related to RV dysfunction and positive TnT, and they can predict intermediate-high mortality risk in acute PE. This study suggests the role of oxidative fibrinogen modifications, which may be caused by hypoxia in the presence of RV dysfunction. Previous reports have shown that there are many post-translational modifications of coagulation and fibrinolytic proteins, including fibrinogen molecule alterations associated with acute pathological conditions, such as inflammation or ischemia [19]. Moreover, our previous clot proteomics studies showed that beyond fibrinogen, many clot-bound proteins can determine its properties, for example platelet-derived factors or histidine-rich glycoprotein [20,21]. Biochemical reactions modifying fibrinogen molecules involve phosphorylation, hydroxylation, sulfation, oxidation, or nitration [19]. Such posttranslational fibrinogen modifications are associated with altered fibrinogen structure and/or function leading to prothrombotic fibrin clot phenotypes, including reduced clot porosity and susceptibility to lysis [22]. We found no differences in fibrinogen levels between PE patients characterized by normal or elevated plasma lactate levels. Heffron et al. [23] showed that fibrin polymerization correlates with fibrinogen nitration. We also did not observe differences in PAI-1 levels, known as a major determinant of CLT [24], in patients stratified according to plasma lactate levels, which suggest other factors involved in hypofibrinolysis in acute PE.

Monocytes and neutrophils, which are the major leukocytes in the inflammatory influx as well as within the venous thrombi generate nitrating metabolic products are able to induce fibrinogen nitration [25]. The myeloperoxidase (MPO), a major protein present in neutrophils, is suspected for promoting nitration [26]. Of note, MPO is a well-established marker of neutrophil activation and NET release. NETosis can be induced in a NADPH oxidase (NOX)-dependent and -independent manner [27]. The NOX-dependent pathway is activated by factors like pro-inflammatory interleukin $1 \beta$, tumor necrosis factor $\alpha$ cytokines, nitric oxide, or oxidized low-density lipoproteins [28-30]. NETosis is an energy-consuming process, and glycolysis in the source of energy during NET formation [27]. Glycolysis generates pyruvate, which under anaerobic conditions is converted to lactate, an end product of glycolysis. Lactate is a waste product of pyruvate metabolism; however, elevated lactate was shown to be associated with shock, sepsis, seizure, cardiac arrest, ischemia, and malignancy [31]. 
Increased lactate accumulation correlated with NET formation, while NET generation was inhibited by lactate dehydrogenase deactivation [27]. Therefore, we assumed that elevated lactate levels in acute PE patients might be considered as an early prognostic marker associated with NET formation, which in the acute thrombotic state can enhance coagulation activation. It should be highlighted that increased lactate levels occur due to enhanced stimulation of energy catabolism. However, coexistence of the inflammatory response can trigger impairment of mitochondrial function leading to metabolic acidosis [32]. We observed almost 45\% increased citH3 levels in acute PE patients with plasma lactate concentrations $\geq 2 \mathrm{mM}$ on admission. The presence of citH3 has been demonstrated within human thrombi, and citH3-positive cells were predominant in organizing thrombi obtained surgically or from autopsy, suggesting that attenuated NETosis may improve thrombolysis [33]. Moreover, extracellular histones, including $\mathrm{H} 3$, have been shown to enhance plasma thrombin generation in vitro [34]. Our data suggests that NET formation in association with increased thrombin generation contributes to slower fibrinolysis a few days since the acute PE symptom onset. A similar observation linking NET formation with fibrinolysis was shown in a recent report on type 2 diabetes [35]. Interestingly, the association of NET-related impairment of plasma fibrinolytic capacity in acute PE patients seems to be independent from fibrinogen or TAFI levels. As shown by Longstaff et al. [14], clots rich in DNA and histones are more resistant to lysis, and this is reversible by DNase. Recently, Mauracher et al. [36] showed that cancer patients with elevated citH3 levels at enrollment experienced more VTE episodes at 2 years than those with lower levels. The relevance of NETosis in acute PE diagnosed in noncancer patients underscores our observation that elevated circulating citH3 in acute PE is linked to higher early mortality risk. This hypothesis-generating study might support the concept that administration of DNase I could provide more effective thrombolytic therapy in acute patients with intermediate high-risk PE [10]. Our study may also suggest that due to a positive charge of NETs, unfractionated heparin (UFH) could be a potentially more effective anticoagulant in acute PE. It might be speculated that UFH could be preferred in acute PE patients in whom there is elevated lactate concentration $\geq 2 \mathrm{mM}$ given a higher probability of suppressing intense NETosis. However, it has been recently shown that in vitro heparin can stimulate NETs formation, while the enoxaparin has a much lower ability to induce NETs than heparin, and fondaparinux does not induce NET formation [37]. The hypothesis on the potential benefits of heparin therapy in the context of real-life PE patients needs to be validated in a separate study.

The limitations of the current study are as follow: First, the studied group was relatively small. Second, high-risk PE patients, cancer and pregnant patients were excluded; therefore, our findings could not be extrapolated to these subsets. Cancer and pregnancy are known prothrombotic factors, which negatively alter fibrin clot phenotype [38,39] and modulate NET formation $[39,40]$. Third, all laboratory parameters were assessed on admission, while hyperlactatemia may be persistent [41] and might modulate inflammatory response and coagulation activation.

In conclusion, increased lactate levels correlated with increased NET formation as well as prothrombotic fibrin clot features, in particular impaired plasma fibrinolytic potential in acute PE patients assessed on admission. This study suggests a new mechanism leading to elevated lactate levels and prothrombotic clot phenotype, which translates to observed associations between elevated lactate levels and increased thrombin generation or enhanced NET formation. The practical implications of the current hypothesis-generating study need to be evaluated in a large group of patients.

Author Contributions: Conceptualization, A.U.; Data curation, M.Z.; Formal analysis, M.Z., J.N., and K.P.M.; Funding acquisition, A.U.; Investigation, A.J.-S., M.J., and A.U.; Methodology, M.Z., J.N., and A.U.; Project administration, M.Z. and J.N.; Resources, A.J.-S., M.J., and A.U.; Supervision, A.J.-S., K.P.M., M.J., and A.U.; Visualization, M.Z.; Writing - original draft, M.Z.; Writing - review and editing, J.N., A.J.-S., K.P.M., M.J., and A.U. All authors have read and agreed to the published version of the manuscript.

Funding: This research was funded by the Polish National Science Centre grant number UMO-2015/B/NZ5/02215. Conflicts of Interest: The authors declare no conflict of interest. 


\section{References}

1. Wendelboe, A.M.; Raskob, G.E. Global Burden of Thrombosis: Epidemiologic Aspects. Circ. Res. 2016, 118, 1340-1347. [CrossRef] [PubMed]

2. Cohen, A.T.; Agnelli, G.; Anderson, F.A.; I Arcelus, J.; Bergqvist, D.; Brecht, J.G.; A Greer, I.; A Heit, J.; Hutchinson, J.L.; Kakkar, A.K.; et al. Venous thromboembolism (VTE) in Europe. The number of VTE events and associated morbidity and mortality. Thromb. Haemost. 2007, 98, 756-764. [PubMed]

3. Liedl, G.; Nazerian, P.; Pepe, G.; Caviglioli, C.; Grifoni, S.; Vanni, S. Different time course of plasma lactate, troponin I and NT-proBNP concentrations in patients with acute pulmonary embolism. Thromb. Res. 2017, 156, 26-28. [CrossRef] [PubMed]

4. Konstantinides, S.V.; Meyer, G.; Becattini, C.; Bueno, H.; Geersing, G.-J.; Harjola, V.-P.; Huisman, M.V.; Humbert, M.; Jennings, C.S.; Jiménez, D.; et al. 2019 ESC Guidelines for the diagnosis and management of acute pulmonary embolism developed in collaboration with the European Respiratory Society (ERS): The Task Force for the diagnosis and management of acute pulmonary embolism of the European Society of Cardiology (ESC). Eur. Respir. J. 2019, 54, 1901647.

5. Kraut, J.A.; Madias, N.E. Lactic acidosis. N. Engl. J. Med. 2014, 371, 2309-2319. [CrossRef]

6. Vanni, S.; Viviani, G.; Baioni, M.; Pepe, G.; Nazerian, P.; Socci, F.; Bartolucci, M.; Bartolini, M.; Grifoni, S. Prognostic value of plasma lactate levels among patients with acute pulmonary embolism: The thrombo-embolism lactate outcome study. Ann. Emerg. Med. 2013, 61, 330-338. [CrossRef]

7. Vanni, S.; Nazerian, P.; Morello, F.; Parisi, M.; Daghini, E.; Pratesi, M.; Bedate, P.; Lobo, J.L.; Jara-Palomares, L.; Portillo, A.K.; et al. Short-term clinical outcome of normotensive patients with acute PE and high plasma lactate. Thorax 2015, 70, 333-338. [CrossRef]

8. Alarcón, P.; Manosalva, C.; Conejeros, I.; Carretta, M.D.; Muñoz-Caro, T.; Silva, L.M.R.; Taubert, A.; Hermosilla, C.; Hidalgo, M.A.; Burgos, R.A. d(-) Lactic Acid-Induced Adhesion of Bovine Neutrophils onto Endothelial Cells Is Dependent on Neutrophils Extracellular Traps Formation and CD11b Expression. Front. Immunol. 2017, 8, 975. [CrossRef]

9. Fuchs, T.A.; Brill, A.; Duerschmied, D.; Schatzberg, D.; Monestier, M.; Myers, D.D.; Wrobleski, S.K.; Wakefield, T.W.; Hartwig, J.H.; Wagner, D.D. Extracellular DNA traps promote thrombosis. Proc. Natl. Acad. Sci. USA 2010, 107, 15880-15885. [CrossRef]

10. Von Brühl, M.L.; Stark, K.; Steinhart, A.; Chandraratne, S.; Konrad, I.; Lorenz, M.; Khandoga, A.; Tirniceriu, A.; Coletti, R.; Köllnberger, M.; et al. Monocytes, neutrophils, and platelets cooperate to initiate and propagate venous thrombosis in mice in vivo. J. Exp. Med. 2012, 209, 819-835. [CrossRef]

11. Stakos, D.A.; Kambas, K.; Konstantinidis, T.; Mitroulis, I.; Apostolidou, E.; Arelaki, S.; Tsironidou, V.; Giatromanolaki, A.; Skendros, P.; Konstantinides, S.; et al. Expression of functional tissue factor by neutrophil extracellular traps in culprit artery of acute myocardial infarction. Eur. Heart J. 2015, 36, 1405-1414. [CrossRef] [PubMed]

12. Thålin, C.; Hisada, Y.; Lundström, S.; Mackman, N.; Wallén, H. Neutrophil Extracellular Traps: Villains and Targets in Arterial, Venous, and Cancer-Associated Thrombosis. Arter. Thromb. Vasc. Biol. 2019, 39, 1724-1738. [CrossRef] [PubMed]

13. Longstaff, C.; Varjú, I.; Sótonyi, P.; Szabó, L.; Krumrey, M.; Hoell, A.; Bóta, A.; Varga, Z.; Komorowicz, E.; Kolev, K. Mechanical stability and fibrinolytic resistance of clots containing fibrin, DNA, and histones. J. Biol. Chem. 2013, 288, 6946-6956. [CrossRef] [PubMed]

14. Gould, T.J.; Vu, T.T.; Swystun, L.L.; Dwivedi, D.J.; Mai, S.H.; Weitz, J.I.; Liaw, P.C. Neutrophil extracellular traps promote thrombin generation through plateletdependent and platelet-independent mechanisms. Arter. Thromb. Vasc. Biol. 2014, 34, 1977-1984. [CrossRef]

15. Ząbczyk, M.; Natorska, J.; Janion-Sadowska, A.; Metzgier-Gumiela, A.; Polak, M.; Plens, K.; Janion, M.; Skonieczny, G.; Mizia-Stec, K.; Undas, A. Prothrombotic fibrin clot properties associated with NETs formation characterize acute pulmonary embolism patients with higher mortality risk. Sci. Rep 2020, in press.

16. Cieslik, J.; Mrozinska, S.; Broniatowska, E.; Undas, A. Altered plasma clot properties increase the risk of recurrent deep vein thrombosis: A cohort study. Blood 2018, 131, 797-807. [CrossRef] [PubMed] 
17. Pieters, M.; Philippou, H.; Undas, A.; De Lange, Z.; Rijken, D.; Mutch, N.J.; Subcommittee on Factor XIII and Fibrinogen, and the Subcommittee on Fibrinolysis. An international study on the feasibility of a standardized combined plasma clot turbidity and lysis assay: Communication from the SSC of the ISTH. J. Thromb. Haemost. 2018, 16, 1007-1012. [CrossRef]

18. Weisel, J.W.; Litvinov, R.I. Fibrin Formation, Structure and Properties. Subcell. Biochem. 2017, 82, 405-456.

19. Zabczyk, M.; Stachowicz, A.; Natorska, J.; Olszanecki, R.; Wiśniewski, J.R.; Undas, A. Plasma fibrin clot proteomics in healthy subjects: Relation to clot permeability and lysis time. J. Proteom. 2019, 208, 103487. [CrossRef]

20. Stachowicz, A.; Zabczyk, M.; Natorska, J.; Suski, M.; Olszanecki, R.; Korbut, R.; Wiśniewski, J.R.; Undas, A. Differences in plasma fibrin clot composition in patients with thrombotic antiphospholipid syndrome compared with venous thromboembolism. Sci. Rep. 2018, 8, 17301. [CrossRef]

21. Undas, A.; Ariëns, R.A. Fibrin clot structure and function: A role in the pathophysiology of arterial and venous thromboembolic diseases. Arter. Thromb. Vasc. Biol. 2011, 31, e88-e99. [CrossRef] [PubMed]

22. Heffron, S.P.; Parastatidis, I.; Cuchel, M.; Wolfe, M.L.; Tadesse, M.G.; Mohler, E.R.; Ischiropoulos, H.; Rader, D.J.; Reilly, M. Inflammation induces fibrinogen nitration in experimental human endotoxemia. Free Radic. Biol. Med. 2009, 47, 1140-1146. [CrossRef] [PubMed]

23. Meltzer, M.E.; Lisman, T.; de Groot, P.G.; Meijers, J.C.M.; Le Cessie, S.; Doggen, C.J.M.; Rosendaal, F. Venous thrombosis risk associated with plasma hypofibrinolysis is explained by elevated plasma levels of TAFI and PAI-1. Blood 2010, 116, 113-121. [CrossRef] [PubMed]

24. Martinez, M.; Cuker, A.; Mills, A.; Lightfoot, R.; Fan, Y.; Tang, W.H.W.; Hazen, S.L.; Ischiropoulos, H. Nitrated fibrinogen is a biomarker of oxidative stress in venous thromboembolism. Free Radic. Biol. Med. 2012, 53, 230-236. [CrossRef] [PubMed]

25. Gaut, J.P.; Byun, J.; Tran, H.D.; Lauber, W.M.; Carroll, J.A.; Hotchkiss, R.S.; Belaaouaj, A.; Heinecke, J.M. Myeloperoxidase produces nitrating oxidants In Vivo. J. Clin. Investig. 2002, 109, 1311-1319. [CrossRef] [PubMed]

26. Awasthi, D.; Nagarkoti, S.; Sadaf, S.; Chandra, T.; Kumar, S.; Dikshit, M. Glycolysis dependent lactate formation in neutrophils: A metabolic link between NOX-dependent and independent NETosis. Biochim. Biophys. Acta Mol. Basis Dis. 2019, 1865, 165542. [CrossRef]

27. Keshari, R.S.; Jyoti, A.; Dubey, M.; Kothari, N.; Kohli, M.; Bogra, J.; Barthwal, M.K.; Dikshit, M. Cytokines induced neutrophil extracellular traps formation: Implication for the inflammatory disease condition. PLoS ONE 2012, 7, e48111. [CrossRef]

28. Patel, S.; Kumar, S.; Jyoti, A.; Srinag, B.S.; Keshari, R.S.; Saluja, R.; Verma, A.; Mitra, K.; Barthwal, M.K.; Krishnamurthy, H.; et al. Nitric oxide donors release extracellular traps from human neutrophils by augmenting free radical generation. Nitric Oxide 2010, 22, 226-234. [CrossRef]

29. Awasthi, D.; Nagarkoti, S.; Kumar, A.; Dubey, M.; Singh, A.K.; Pathak, P.; Chandra, T.; Barthwal, M.K.; Dikshit, M. Oxidized LDL induced extracellular trap formation in human neutrophils via TLR-PKC-IRAK-MAPK and NADPH-oxidase activation. Free Radic. Biol. Med. 2016, 93, 190-203. [CrossRef]

30. Andersen, L.W.; Mackenhauer, J.; Roberts, J.C.; Berg, K.M.; Cocchi, M.N.; Donnino, M.W. Etiology and therapeutic approach to elevated lactate levels. Mayo Clin. Proc. 2013, 88, 1127-1140. [CrossRef]

31. Robergs, R.A.; McNulty, C.R.; Minett, G.M.; Holland, J.; Trajano, G. Lactate, not Lactic Acid, is Produced by Cellular Cytosolic Energy Catabolism. Physiology 2018, 33, 10-12. [CrossRef] [PubMed]

32. Savchenko, A.S.; Martinod, K.; Seidman, M.A.; Wong, S.L.; Borissoff, J.I.; Piazza, G.; Libby, P.; Goldhaber, S.Z.; Mitchell, R.N.; Wagner, D.D. Neutrophil extracellular traps form predominantly during the organizing stage of human venous thromboembolism development. J. Thromb. Haemost. 2014, 12, 860-870. [CrossRef] [PubMed]

33. Ammollo, C.T.; Semeraro, F.; Xu, J.; Esmon, N.L.; Esmon, C.T. Extracellular histones increase plasma thrombin generation by impairing thrombomodulin-dependent protein C activation. J. Thromb. Haemost. 2011, 9, 1795-1803. [CrossRef]

34. Bryk, A.H.; Prior, S.M.; Plens, K.; Konieczynska, M.; Hohendorff, J.; Malecki, M.T.; Butenas, S.; Undas, A. Predictors of neutrophil extracellular traps markers in type 2 diabetes mellitus: Associations with a prothrombotic state and hypofibrinolysis. Cardiovasc. Diabetol. 2019, 18, 49. [CrossRef] [PubMed] 
35. Mauracher, L.M.; Posch, F.; Martinod, K.; Grilz, E.; Däullary, T.; Hell, L.; Brostjan, C.; Zielinski, C.; Ay, C.; Wagner, D.D.; et al. Citrullinated histone H3, a biomarker of neutrophil extracellular trap formation, predicts the risk of venous thromboembolism in cancer patients. J. Thromb. Haemost. 2018, 16, 508-518. [CrossRef] [PubMed]

36. Zabczyk, M.; Królczyk, G.; Czyżewicz, G.; Plens, K.; Prior, S.; Butenas, S.; Undas, A. Altered fibrin clot properties in advanced lung cancer: Strong impact of cigarette smoking. Med. Oncol. 2019, 36, 37. [CrossRef]

37. Lelliott, P.M.; Momota, M.; Shibahara, T.; Lee, M.S.J.; I Smith, N.; Ishii, K.J.; Coban, C. Heparin induces neutrophil elastase dependent vital and lytic NET formation. Int. Immunol. 2019. [CrossRef]

38. Pretorius, E.; Bronkhorst, P.; Briedenhann, S.; Smit, E.; Franz, R.C. Comparisons of the fibrin networks during pregnancy, nonpregnancy and pregnancy during dysfibrinogenaemia using the scanning electron microscope. Blood Coagul. Fibrinolysis 2009, 20, 12-16. [CrossRef]

39. Garley, M.; Jabłońska, E.; Dabrowska, D. NETs in cancer. Tumour Biol. 2016, 37, 14355-14361. [CrossRef]

40. Giaglis, S.; Stoikou, M.; Sur Chowdhury, C.; Schaefer, G.; Grimolizzi, F.; Rossi, S.W.; Hoesli, I.M.; Lapaire, O.; Hasler, P.; Hahn, S. Multimodal Regulation of NET Formation in Pregnancy: Progesterone Antagonizes the Pro-NETotic Effect of Estrogen and G-CSF. Front. Immunol. 2016, 7, 565. [CrossRef]

41. Biegus, J.; Zymliński, R.; Gajewski, P.; Sokolski, M.; Siwołowski, P.; Sokolska, J.; Swoboda, K.; Banasiak, M.; Banasiak, W.; Ponikowski, P. Persistent hyperlactataemia is related to high rates of in-hospital adverse events and poor outcome in acute heart failure. Kardiol. Pol. 2019, 77, 355-362. [CrossRef] [PubMed]

(C) 2020 by the authors. Licensee MDPI, Basel, Switzerland. This article is an open access article distributed under the terms and conditions of the Creative Commons Attribution (CC BY) license (http://creativecommons.org/licenses/by/4.0/). 